\title{
Spiritual and Secular Existential Meaning-Making Coping Methods among Japanese Cancer Patients
}

\author{
Fereshteh Ahmadi ${ }^{1}$, Mohammad Rabbani ${ }^{2}$, Xiaohe Yi $^{3}$, Hiroko Kase ${ }^{3}$, Nader Ahmadi ${ }^{4}$ \\ ${ }^{1}$ Department of Social Work and Psychology, Faculty of Health and Occupational Studies, University of Gävle, Sweden \\ ${ }^{2}$ Faculty of Law \& Political Science, University of Tehran, Tehran, Iran \\ ${ }^{3}$ Department of Health Sciences and Social Welfare, School of Human Science, Waseda University, Tokyo \\ ${ }^{4}$ Swedish Agency for Work Environment Knowledge, Gävle, Sweden \\ Correspondence: Mohammad Rabbani, Faculty of Law \& Political Science, University of Tehran, Tehran, Iran.
}

Received: September 17, 2019

Accepted: October 8, $2019 \quad$ Available online: October 18, 2019

doi:10.11114/ijsss.v7i6.4527

URL: https://doi.org/10.11114/ijsss.v7i6.4527

\begin{abstract}
The present article is written on the basis of a sociological international project on meaning-making coping. The aim of the project has been to understand the role of culture in meaning-making coping. The project embarrasses studies among cancer patients in 10 countries. The present article is confined to the results obtained in the study in japan. The main aim was to investigate the impact of culture from a sociological perspective on the choice of coping methods. Twelve participants with various kinds of cancer were interviewed.

Several meaning-making coping methods are found in the present study. This study underlines the importance of investigating cultural and social context when investigating into the use of the meaning-making coping methods in different countries.
\end{abstract}

Keywords: meaning-making coping, cancer, Japan, meaning-making coping methods

\section{Introduction}

During recent decades, the importance of existential questions in health has received considerable attention. Several studies have focused on the role of religiosity and spirituality in disease treatment (Pargament, 2007; Cobb, Puchalski \& Rumbold, 2012; Koenig, King \& Carson, 2012; Padela \& Curlin, 2012), while others have expressed doubt about the importance and effectiveness of such coping methods for seriously ill patients (Sloan \& Bagiella, 2001; Powell, Shahabi \& Thoresen, 2003; Sloan, 2006; Poole \& Higgo, 2010). Several researchers have suggested that there is no clear evidence to show that "spirituality" is related to well-being (Sloan and Bagiella, 2001, 2002; Thoresen, 1999, 2002). Some have been critical of applying the notion of spirituality to health-related matters, asserting that "spirituality" basically ignores psychology and reduces existential philosophy to issues of "spiritual" well-being (Salander, 2015, p.24).

When examining the role of religion, spirituality, and existential issues in health, one important problem is that many studies in this area have neglected non-religious populations.

Recently, however, more attention has been paid to secular societies and how secular

individuals cope with a variety of crises (Ahmadi \& Ahmadi, 2018; Ahmadi, 2006, 2015; Ahmadi \& Ahmadi, 2015; La Cour \& Hvidit, 2010; Moylan, Carey, Blackburn, Hayes \& Robinson, 2015). In secular societies, the dominant culture and ways of thinking leave little scope for religion to play an important role in people's lives. Sweden and Japan can be considered examples of such societies (Note 1). This being the case, one important question to ask is: Besides the RCOPE methods, what kinds of spiritual or secular existential meaning-making coping methods are used by non-theists or non-religious people when they face difficult situations? What role do culture and ways of thinking play in the choice of meaning-making coping methods, including spiritually oriented or secular existential coping methods? To address these questions, several studies have been conducted, within the framework of an international project, on the meaning-making coping methods (religious, spiritual and existential) used by cancer patients in a number of countries (Ahmadi \& Ahmadi, 2018). These studies have revealed the impact of culture and ways of thinking on the use of meaning-making coping methods when people are facing a crisis. One of these countries was Japan. In the current article, we present our results on 
the meaning-making coping methods used by cancer patients in Japan.

The aim of the study was twofold: A) to investigate the meaning-making coping methods used by Japanese people to cope with stressors, and B) to study the impact of culture in choosing these methods.

\section{Theoretical Framework}

\subsection{Coping and Culture}

Before considering the role culture plays in coping, it would seem necessary to define what we mean by culture. When we refer to culture, we mean a system of norms and values that is shared by members of a society, community or group as well as explicit expressions of these norms and values. Norms and values are needed to construct an individual's identity and ethical/moral world, which in turn functions as an orienting system in social relationships. Thus, an individual's belief system, ways of thinking and lifestyle are primarily culturally constructed. Culture impacts the "complex whole" of social life: its institutions, laws, knowledge, customs, morals and lifestyles (Taylor, 1968).

Because it is embedded in culture, coping takes different shapes. As Pargament (1997, p.117) suggests: "Coping plays out against the background of larger cultural forces. In the language of coping, culture shapes events, appraisals, orienting systems, coping activities, outcomes, and objects of significance". Put differently, culture provides the foundation in our search for significance (Pargament, 1997, p.119). Aldwin (2000, p.193) suggests four ways in which culture can influence stress and the coping process:

First, the cultural context shapes the types of stressors that an individual is likely to experience. Second, culture may also affect the appraisal of the stressfulness of a given event. Third, cultures affect the choice of methods that an individual utilizes in any given situation. Finally, the culture provides different institutional mechanisms by which an individual can cope with stress.

However, stressing the essential role of culture in determining individuals' behaviors, attitudes and views does not mean that culture is the only factor affecting coping. It is likely that gender, age, socioeconomic status, education, development throughout life, social security systems like medical/social care and mental health also have a significant role to play in coping.

The notion that cultural and social forces influence how people cope with crises does not imply that coping lacks an "individual character." By "individual character," we are referring to the role personal characteristics play during the coping process. What is emphasized in particular here is individuals' role as decision-makers. Nonetheless, the "individual character" of coping does not decrease culture's role in coping. Culture - an essential factor in shaping the individual's identity - is also present in the decision-making process. The "individual character" of coping actually reveals the non-deterministic character of coping-related choices. It also makes it meaningful to study which types of individual characteristics are helpful or harmful during the coping process.

Starting from a cultural perspective, we have tried to discover the impact of culture as regards encouraging or discouraging the use of spiritual and secular existential meaning-making coping. The project, to which the study in Japan belongs, is an additional step forward in investigating the role of culture in meaning-making coping in societies where religion is not an integrated part of individuals' lives, but where spirituality and existential issues matter.

\subsection{Meaning-Making Coping}

Many studies focused on coping have used the terms "religious" and "spiritual" to refer to coping methods that are essentially existential in nature. Nevertheless, a number of studies (Ahmadi, 2006; Ahmadi \& Ahmadi, 2015; Ahmadi, Park, Kim \& Ahmadi, 2016; Ahmadi \& Ahmadi, 2018) have revealed the use of other coping methods that can hardly be considered religious or spiritual, for instance, methods that are tied to nature. Coping methods such as these can be defined as existential in nature, entailing a search for meaning that has no connection at all to religion or religious symbols, or no apparent connection to a sacred religious/spiritual source. The term existential coping is used because such methods involve individuals' efforts to find an inwardly source - in nature, themselves or others - that can help them cope with the problems they are facing. These problems have resulted in an existential vacuum that requires developing the old order into a new order - a new order that can help them fill this vacuum. Figure 1, first presented by Ahmadi \& Ahmadi (2018), depicts a model of the relation between religious, spiritual and secular existential coping in our project. 


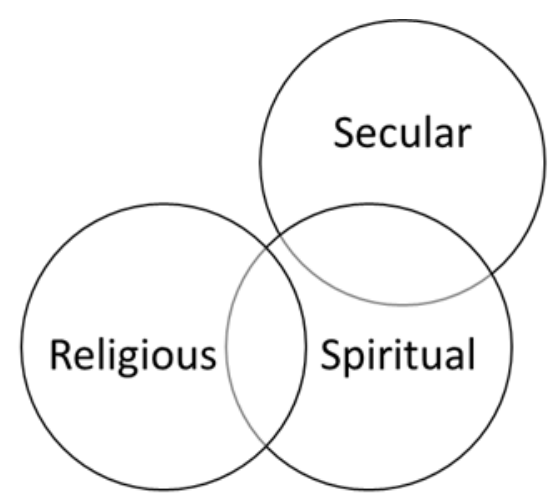

Figure 1. Relation of existential meaning-making domains (Ahmadi \& Ahmadi, 2018)

According to this model (see Figure 1), the concepts and topics that are part of the religious and spiritual domains overlap to some degree. The concepts and topics belonging to spiritual and secular meaning-making coping overlap too, but it is important to note the lack of overlap between secular and religious concepts and topics (Ahmadi \& Ahmadi, 2018, p.136). This is because we define religion as a search for significance that unfolds within a traditional sacred context (Ahmadi, 2006, p.72). Moreover, we define spirituality as a search for connectedness with a sacred source that is related or not related to God or any religious holy sources (Ahmadi, 2006, p.72-73). Thus, as we can see, secular meaning-making coping has practically no point of connection with traditional sacred contexts, but it can intersect with a person's search for connectedness with a sacred source without any reference whatsoever to God or traditional religious contexts.

In the present study, the term meaning-making coping has been used to refer to the whole range of religious, spiritual and existential coping methods.

\section{Methodology}

In the present study, semi-structured qualitative interviews were employed to identify the meaning-making coping methods used by middle-age and older cancer patients. The Japanese colleagues were responsible for gathering data among the Japanese informants.

\subsection{Participants}

In total, 12 informants ( 3 females and 9 males aged 51 and older) participated in Tokyo and its surrounding suburban areas.

The informants had various types of cancer; their stage of cancer varied from the earliest to palliative care (for detailed information on the informants' demographic characteristics (see table 1).

Table 1. Characteristics of the Participants

\begin{tabular}{llllll}
\hline No. & Age & Gender & Education & Type of Cancer & Diagnosis date Now \\
\hline 1 & 81 & male & Bachelor's & Prostate cancer & 4 years \\
2 & 71 & male & Bachelor's & Gastric cancer & 23 years \\
3 & 56 & male & Master's & N/A & N/A \\
4 & 66 & male & Bachelor's & Lung cancer & 13 years \\
5 & 64 & female & Bachelor's & Breast cancer & 10 years \\
6 & 79 & male & Master's & Gastric cancer & 11 years \\
7 & 70 & male & Bachelor's & Liver cancer & 14 years \\
8 & 71 & male & College dropout & Prostate cancer & 2 years \\
9 & 75 & male & PhD & Colon cancer & 19 years \\
10 & 75 & male & Bachelor's & Ear canal cancer & 5 years \\
11 & 51 & female & Bachelor's & Breast cancer & N/A \\
12 & 61 & female & Bachelor's & Breast cancer & N/A \\
\hline
\end{tabular}

\subsection{Interview Guide}

The interview questions used in the present study were mainly based on the results of the studies conducted by Author in Sweden (Ahmadi, 2015) and other countries. Some questions were of course modified to better reflect the Japanese culture (see Appendix). 


\subsection{Procedure}

The interviews were conducted in 2016, and the transcription process was completed in the same year. After all of the interviews had been transcribed and analyzed, the main citations (participants' responses and statements) for each category were translated into English by the researchers. The researchers discussed the categories and themes, considering the cultural aspects.

\subsection{Method of Analysis}

Just as was done in the other studies in the international project, following translation of the transcribed interviews, the interview protocols were coded on the basis of the themes identified in the study using a thematic analysis method (Braun $\&$ Clarke, 2006). Subsequently, the categories and sub-categories were connected to the relevant codes in the transcription data. Coding continued until a high level of inter-rater agreement was achieved.

After completion of the coding process, we identified the central characteristics of the methods used by the informants to cope with their cancer disease. To accomplish this, we started from the project aim, using previous findings from the larger project. After identifying various themes, we began by categorizing themes, a process that was partly based on the findings obtained in other project studies (Ahmadi, 2006; Ahmadi, 2015; Ahmadi, Park, Kim \& Ahmadi, 2016; Ahmadi, Park, Kim \& Ahmadi, 2017; Ahmadi \& Ahmadi 2018; Ahmadi et al., 2018).

\section{Trustworthiness}

In the present research, the criteria suggested by Lincoln and Guba (1985) were employed to ensure trustworthiness. The requirement for reliability was met by ensuring that there was variation in the informants' type of cancer, age, gender and education. The researchers have demonstrated their continued commitment to the area under study. All members of the research group carefully checked all of the interview drafts and verified all of the codes and categorizations.

\section{Ethical Considerations}

Before beginning the research, the present study was approved by the regional Ethics Board in Uppsala, Sweden 2015. Subsequently, Waseda University reviewed the project to ensure that it complied with the Research Code of Conduct and Ethics from 2016. Note that the interviews were conducted and audio-recorded only after obtaining the informants' informed consent. Furthermore, all potential informants were told that the research is part of an international study focused on identifying the methods cancer patients use to cope with their illness; participation was voluntary; participants could withdraw at any time or from any part of the study without suffering any consequences; the data are kept confidential; and the research findings have been presented and published without mentioning the informants' names or any representative characteristics.

\section{Results and Discussion}

In this section, we present the results on the spiritual and secular meaning-making coping methods. We also discuss the findings from a cultural perspective.

We found 11 meaning-making coping methods used by participants in the present study (see table 2).

Table 2. List of spiritual and secular meaning-making coping methods
(1) Ignoring the illness
(2) Fatalism
(3) Connectedness with deceased Ancestors
(4) Connectedness with People (Altruism)
(5) Connectedness with Nature
(6) Pragmatism/Trust in Science
(7) Body-Mind connection
(8) Discourse of the Self
(9) Visualization
(10) Positive Solitude
(11) Positive thinking

\subsection{Ignoring the Illness}

Ignoring the illness is one of the coping methods we identified in our study among Japanese patients. Using this method, the patient tries to manage the situation by normalizing the illness and making it a part of normal daily life. In this respect, the patient ignores the intensity of the illness and does not think about it as a crisis; daily life continues as usual.

In the following, we witness how this method is clearly used by one interviewee, a 79-year-old man: 
"I was not that worried when I got cancer. When our interview is finished, I'll go to play golf with my friends. There are so many things to do every day, so I don't have much time to think about my disease."

Another interviewee, a 75-year-old man, explained using this method as follows:

"When I was diagnosed with cancer, I did nothing, just as usual. Just take things the way they are."

It seems that use of this method is rooted in the principle of adaptability, which is one of the virtues associated with Bushido. Bushido is a collective term for many codes of honor and ideals that dictated the samurai way of life (Matthews, 2007). It teaches that one should adapt to all circumstances one faces, such as stressors, illnesses or crises.

From a cultural sociological perspective, we can also explain use of this method as follows: Militarism inherited the Bushido spirit, which was the most powerful ideology among the nations during World War II, when these interviewees were growing up. Van Wolferen (1990) describes Japanese society after World War II as follows:

"In its 'fighting spirit', its compulsory togetherness, its consciousness of rank within the company and more especially its propriety treatment of the employee as a 'family' member, in a way that hinders his development as an independent individual, 'salaryman life' is clearly reminiscence of military tradition."

This explains why many of the male informants in their 70s, who used to work hard for their company, feel that expressing personal weakness and anxiety is shameful. Ignoring illness and continuing a "normal" life is therefore an integrated part of the ways of thinking in Japan.

\subsection{Fatalism}

Believing in chance or in fate is a method we witnessed among Japanese cancer patients. We call it Fatalism. It is a way of accepting one's situation when facing cancer. In such a situation, the patient does not ignore the hardship of the disease, but continues her/his daily life. Such a coping method is the result of belief in the idea of 'good luck' or 'bad luck,' where one has no control over one's circumstances. The main difference between 'Ignoring the illness' - as mentioned above - and this method concerns being passive or active when dealing with the illness. Patients using the Ignoring the Illness method normalize and accept the situation actively and try to find a solution - or at least they plan to fill every moment with pleasure. A fatalist cancer patient accepts her/his condition passively and does not follow the treatments or find a way to resolve the situation. Such a patient just waits and believes she/he cannot change her/his destiny.

In this regard, a 56-year-old man told us the following:

"I have given up anti-cancer therapy, because it was very painful to take the therapy and I could not go to my work. Now I don't take any anti-cancer treatment anymore and work as usual. I take things as they are and choose to accept my fate."

One 66-year-old man explained using this method in the following way:

"After my cancer diagnosis, I looked forward. And I thought that even if I can’t live, just let it be."

Another informant, a 79-year-old man, said:

"I think all the things we have experienced are determined by our luck...I believe in luck. I also believe that I've been able to live until today because of my luck too... When I was in Syria, the hotel I stayed in was attacked by a bunch of terrorists. But that day I left the hotel earlier than usual because I had some business to do. Some people were killed and kidnapped, but I survived. I don't think I was saved by God. I think I was saved by my luck."

It seems that Fatalism is somehow tied to Zen Buddhism. In Zen Buddhism, a person's status is unimportant, as every person will get sick, age, die, and eventually be reincarnated into a new life. The suffering people experience during life is a way for them to gain a better future, and this is the Fate and the way to escape the cycle of death and rebirth by attaining true insight (Watt, 2003). Belief in such an idea can result in a passive encounter with cancer in the form of a coping strategy that we call Fatalism.

It is interesting that even interviewees who reported not believing in the 'next life' or 'reincarnation' reduced pain by accepting their situation as it is. Here we see the role of Zen Meditation, which emphasizes awareness of where we are and what we are doing, and not becoming overly reactive or overwhelmed by what is happening around us. Based on Zen Meditation, the concept of Mindfulness has been formed and applied to stress reduction and medical treatment as 
well as used in clinics and hospitals. Here the coping method is a means that leads to the concept of mindfulness-based cognitive therapy.

\subsection{Connectedness with Deceased Ancestors}

Calling on Spirits of Ancestors for help or expecting to receive ancestral healing is a spiritual coping method we witnessed among some Japanese cancer patients. We have observed ancestor worship in many societies, particularly in China, Vietnam, parts of Africa, Mexico, and among certain indigenous American tribes. Praying for the spirits of ancestors is also common in Japan; it would seem that ancestor worship among the Japanese has yet to change significantly (Morioka, 1984): Rather than being a religious or ritual behavior for protection of the spirits of the ancestors, it is now a spiritual practice aimed at receiving protection or healing for oneself. Such an approach to ancestor worship was used by some informants in our study.

In this regard, one of the informants, a 51-year-old woman, explained using this method:

"After my diagnosis, I went to visit my grandparents' grave and talked to them. I told them that I was ill and that I would keep trying."

Also, another informant, a 75-year-old man, said:

"I believe we are protected by our ancestors...I think we are not living by ourselves, we are allowed to live... We should know that maybe our own efforts played a role in our survival, but the strength that really supports us has come from others."

Finding the roots of using this coping method among the Japanese could lead us to the teachings of Confucianism. The Philosophy of Confucianism is widespread in Japanese culture (Sharf, 1993). The effect of Filial Piety on the Connectedness with deceased Ancestors can be highlighted as a principal of Confucianism. Filial piety does not only entail being good to one's parents and ancestors (Sung, 2001), but also involves the role parents and ancestors play for the child. The parents' virtues are to be practiced, regardless of the child's piety, and vice versa (Jordan, 1998). On the other hand, Filial piety does not only extend to how children behave toward their parents and ancestors, but also involves children being grateful for the human body they received from their parents and ancestors (Sung, 2009). In this respect, because the body is seen as an extension of one's parents and ancestors, there are prohibitions on damaging or hurting one's body, which is a heritage (Kwan, 2000). In this kind of circumstance, and in such a conceptual framework of meaning making, when a mutual relation is witnessed between oneself and one's ancestors (even those who are deceased), it is very likely that a person would ask her/his ancestors for help in protecting her/his body from cancer or another serious disease.

\subsection{Connectedness with People}

This method is a transcendent feeling of unity and being one with other human existences. Here, connectedness with people is a way to empower the person to cope with his/her illness.

Explaining use of this method, a 75-year-old man told us the following:

"When we are faced with a severe illness and survive, we should know that maybe our own efforts helped in our survival, but the strength that really supports us has come from others. So, I decided to repay and contribute to society"

In this connection, another informant, a 61-year-old woman, told us the following:

"The greatest help came from other cancer survivors...I talked to other cancer survivors and was saved by them because I am not the only one who is experiencing pain... I get energy from the cancer patients' association."

We also find an emphasis on regarding such connectedness as spiritual; in this regard, a 75-year-old man said:

"When I was with my friends, I could feel the spiritual connection between them and me."

In another case, we are witnessing positive thinking on the patient's part. One 56-year-old man said:

"I can feel the spiritual connection between people... the relationship between people can help you fix a lot of things. Through relationships with others, I can get healed, feel the strength and think positively."

The roots of using this method in Japan can be traced back to a time before Confucian philosophy, to Japanese mythology. A translation of "Ko-Ji-Ki" by Chamberlain (1883) shows that, in Japanese mythology, empathy and identifying oneself with others are highly valued. By contrast, actions that are individualistic or antisocial (that harm others) are condemned. Furthermore, Japanese people learn to get along with others, which is called Wa (Whiting, 
1989). In Japanese culture, interdependence, including a sense of sympathy for others, is so strong that Takeo Doi, a Japanese psychoanalyst, argued that in Japan Amae (Note 2) or dependency is encouraged in interpersonal relationships; dependency has its roots in the interdependency between parent and child (Johnson, 1993)

\subsection{Connectedness with Nature}

Connectedness with Nature is a spiritual and existential meaning-making coping method used by the Japanese cancer patients in our study. Connectedness with nature, as a way to cope with cancer, is emphasized by the respondents. Here, it seems that there are two ways to make such a connection. One is the belief in some spiritual, invisible and transcendent power, and the other is a physical worldly approach to an "eternal entity" called Nature. The latter approach - involving such activities as walking in the mountains, eating organic food and listening to bird song or the sound of rivers - is more existential and not necessarily spiritual. Using both patterns, patients try to gain power by connecting with an everlasting resource.

One interviewee, a 66-year-old man, explained this as follows:

"I feel I got energy from nature. Therefore, I often went to places where I could see a lot of nature... I also practiced Qigong (Note 3) to get power from the air."

Another informant, a 64-year-old woman, told us about her thoughts and feelings during her illness as follows:

"I can feel that a human being is part of nature. We are not living by ourselves. We are allowed to

live by nature... when I was in nature, I felt its greatness... my heart was very devoted to nature.

Nature is great."

Also, one of our interviewees, a 70-year-old man, told us the following:

"I think I can get power from nature, by nature here I do not merely mean trees or natural views. I

think the food we eat, our body and our mental world are all part of nature."

One 61-year-old woman talked about her coping method connected to nature:

"I realized that human beings are part of nature. We came from nature and will eventually go back

to it. I have a feeling of intimacy with nature now. I didn't think too much about it until I got

cancer. I liked walking ... in areas surrounded by a lot of greenery."

We have found that coping through connectedness is a very important method among our Japanese informants, as well as among informants in the other countries studied within the framework of our project (Ahmadi, 2006; Ahmadi, 2015; Ahmadi \& Ahmadi, 2015; Ahmadi et al., 2016; Ahmadi \& Ahmadi, 2018).

In the case of Connectedness with Nature, in addition to the Bushido's teachings, the ancestral religion of Japanese should also be considered. In this regard, the samurai creed says that one has no parents except the earth and the sky. It seems that some of the teachings of Shintoism can be associated with the nature-oriented coping method.

In Shintoism, the belief is that Kami (Note 4), a Shinto deity or spirit, is present in all of nature, including rocks, trees, and mountains. Humans can also be considered to possess a Kami. One of the goals of Shintoism is to maintain a connection between humans, nature, and Kami (Watt, 2003).

\subsection{Pragmatism/Trust in Science}

One of the meaning-making coping methods considered in the present study is pragmatism, which manifests itself in Trust in Science. In fact, by using this method, people try to acquire the feeling of possessing power by connecting to an 'eternal entity' that serves as a power resource (Ahmadi et al., Forthcoming). In our study in Japan, we found that science is an "eternal entity" that one can be empowered by when facing a crisis situation if one trusts in it and feels connected to it. The following citations display use of Trust in Science as a coping method. One interviewee, a 71-year-old man, told us the following:

"From the time I faced my crisis [caused by cancer], I always believed in scientific judgment."

Another interviewee, a 71-year-old man, explained using this method in this manner:

"Well, with the rapid development of medical science, I believe that if you try your best, the appropriate treatment will come out eventually. We should believe in science."

Trust in Science may seem to be a modern phenomenon, but some strong social and cultural "roots" can be found that explain such a rationalist approach among our interviewees, many of whom are quite elderly. In 1947, when our interviewees were children, the average life span was around 50 years. Rapid improvements in medical care and medical service extended the life span of Japanese people by 30 years, and this progress was made within a 20-year period. The rate of cancer survival increases annually. Given these facts, almost all of the interviewees trust that 
scientific medical treatment will help them. Interestingly, the same people also emphasize their own efforts to recover. Besides this factor, it should be noted that Confucian philosophy and Bushido virtues both stress the importance of Wisdom (Sharf, 1993). According to this approach, success can come only if decisions are made after consulting with others, especially experts. This style of consultative decision-making involves others in an information exchange and makes implementation of the decision smoother. The idea of Trust in Science is a modern one, although in Japan it can be traced back to the prevalence of Confucian ideas concerning the practical conditions of human life and a kind of pragmatism (Stephens, 2009, p.55). Unlike the other ancient philosophical schools of thought, in Confucianism there is a strong tendency toward pragmatism. As Stephens (2009, p.55) mentions:

"According to Confucius, the purpose of philosophic thought and knowledge was the improvement of the human condition through the cultivation of the individual. Knowledge and understanding are not sought merely for their own sake, but rather as a means toward instructing the individual in his or her life".

Pragmatism - a feature of Japanese ways of thinking - can then be regarded as a cultural factor that may have impacted our interviewees as regards their trust in science. In Japan, there is a saying 'Do the likeliest and Ten will do the best.' Ten refers to a high power in the sky, like kami (Gods), nature, destiny and ancestors. Our interviewees were educated in the principles of good behavior in life through the use of such sayings. Thus, although they turn to a higher power for help, they know they should make efforts to be cured, and turning to science is such an effort.

\subsection{Body-Mind Relationship}

Another remarkable strategy found in the interviews is the respondents' approach to the relationship between the body and the mind. It is believed that there is a mutual relationship between physical and mental functioning. Hence, a negative mental state can cause dysfunctional situations. In our study, based on such a belief some of the interviewees reported having tried to improve their mental state and reinforce their body's struggle with cancer through mental exercises. Concerning this method, one 70-year-old man mentioned the following:

"I believe that the human body is connected to the mind. We cannot just focus on one side. When I do meditation...I feel my body is also training."

Another interviewee, a 75-year-old man, told us:

"I believe mental health is connected to physical health. The stronger your mental world is, the more likely it is you will survive cancer."

Besides native religion (belief in Kami), the culture of Japan today is profoundly impacted by Shintoism and Buddhism. We seem to have found some common roots between certain coping methods identified in the present study and some of the teachings of Zen Buddhism. One of these methods is Body-Mind connection, which seems to be related to Zen Meditation.

According to Japanese Buddhism, there is a harmony and connection between the body and the mind. Furthermore, in Japan the relationship between physical and mental health is taught from childhood. There is a famous saying: "a healthy spirit lives in a healthy body." Thus, a negative state in either mind or body can cause a negative state in the other. In line with this notion, one should try to achieve synchronicity and a balance in energy between mind and body (Shaner, 1985). Achieving this synchronicity and balance could be done by practicing meditation (mind) and eating healthy food/engaging in exercise such as Tai Chi or Yoga (body).

\subsection{Discourse of the Self}

When using the spiritual connection method (one of the RCOPE methods) (Ahmadi et al., 2018), the person is looking for a stronger connection with God or a spiritual person. Regarding the Discourse of the self as a coping method, one does not seek a spiritual connection with God or another out-worldly spiritual source, but a spiritual connection with oneself. This entails searching for an inner power that may help the person cope with illness-related stress. Secular existential meaning-making coping is thought of as the mental picture one has of oneself; it consists of the lessons learned through personal experience and by internalizing others' judgments.

When faced with a severe disease like cancer, the individual must assume a new role. This role changes how the victim is viewed, which in turn affects how the person is perceived. This affects the individual's method of facing and coping with her/his illness.

We found two patterns concerning the Discourse of the Self as a coping method:

\subsubsection{Personal Strength Discourse}

The first pattern involved using a personal strength discourse as a self-protection mechanism. To explain this 
mechanism, for instance, one 81-year-old man said:

"I try not to look for peace and security through God. I try to find peace by myself and control myself."

In another case, a 75-year-old man said:

"When I faced cancer, I knew I had to make myself strong, which means I had to survive cancer, I

had to fight the cancer. In order to do that, I had to make my heart stronger."

As the above citations show, these interviewees have found it important to face their disease, the first one by trying to control his life and the second by fighting the cancer.

\subsubsection{Having a Mission}

The second pattern is having a mission. In this regard, a 51-year-old woman told us:

"When I got cancer..., I thought I still have things to do... I realized it's not the end because I still

have things to do ... I have to be cured; I have to survive, for my children."

The strong emphasis on Duty in Japanese ways of thinking has apparently played an important role in this coping method. Here we address the relation between Giri and both patterns of the coping method the Discourse of the Self. Giri is one of the eight main virtues of Bushido as envisioned by Nitobe (2002), who teaches that each person is responsible for everything she/he has done and said and for all of the consequences that follow (Nitobe, 2002).

\subsection{Visualization}

One of the holistic health methods used by informants is visualization, which can be seen as a secular existential meaning-making coping method. As Shafer \& Greenfield (2000) explain, visualization is the language the mind uses to communicate as well as to make sense of the inner and outer world. The technique of visualization - also called guided imagery - involves having the patient imagine positive images and desired outcomes in association with specific situations. It is thought to promote physical, mental and emotional health. Imagery is connected to our awareness of sensory (physical) and perceptual (cognitive) experiences (Heinschel, 2002). The present focus is on imagination and understanding the meaning of "pictures in the head," as the notion applies to health and well-being.

In this regard, one interviewee, a 75-year-old man, described using this method as follows:

"I tried meditation therapy when I got cancer, to imagine that the cancer cells flowing through my body were being destroyed."

Also, one 61-year-old woman said:

"Sometimes I would try imagining things inside my brain. For example, when I felt depressed and tired, I imagined what I would look like when I was cured and healthy again.”

It seems that, with regard to the Visualization method, there are some modern approaches to the issue. We could not find any clear footprint of ancient Japanese culture or the native religion.

\subsection{Positive Solitude}

Another secular existential meaning-making coping method our informants used to cope with their cancer is Positive solitude. Preferring to be alone so that one can think is one of the methods used by our Japanese informants to cope with the anxiety and stress caused by cancer. Two informants mentioned that they enjoyed being by themselves during this difficult period. We chose the term Positive solitude for this attitude because implies an appreciation of being alone.

One 56-year-old man described this method as follows:

"I used to be alone and think about my life. I would think about my way of living or the end of life. It's more like asking myself questions and thinking about my life story."

In another case, a 64-year-old woman said:

"I used to be alone and to think about the meaning of life...Thinking about life is a very important part of life. When I was healthy... I never thought about how valuable it is to just live in the world. And then, I got cancer; now I know the value of life."

Sometimes becoming seriously ill gives individuals the opportunity to look into their self and search for questions they have rarely had time to consider. Positive solitude is not only a method of avoiding exhaustion and promoting feelings of tranquility, but also, as our informants explained, a way of reviewing life events and reconstructing one's view of life. 
Positive solitude can be related to the teachings of Buddhism, which stress individual salvation (Traylor, 1988). Sarvananda (2012) explains that 'Buddhism challenges us to train ourselves to be more and more at ease in our own company,' as well as 'to try and be with ourselves without distraction.'

The Buddha made a distinction between physical and psychological solitude. He considered physical solitude to be the more important of the two. In his view, psychological solitude meant isolating the body-mind from negative thoughts and emotions, something that is a natural human experience that can result in positive change and, thus, should not be avoided (Astor, 2014)

\subsection{Positive Thinking}

As Naseem \& Khalid (2010, p.42) argue:

"Positive thinking is looking at the brighter side of situations. It makes a person constructive and creative. The authors explain (Naseem \& Khalid, 2010) "positive thinking is related with positive emotions and other constructs such as optimism, hope, joy, and wellbeing".

As suggested by Naseem \& Khalid (2010, p.43):

"McGrath (2004) defined positive thinking as a generic term referring to an overall attitude that is reflected in thinking, behavior, feeling and speaking. Positive thinking is a mental attitude that admits into the mind; thoughts, words and images that are conducive to growth, expansion, and success."

Our study in Japan has revealed that cancer patients' painful journey can make them feel more grateful in their present life, bringing about a turning point in their life and causing them to adopt a new positive attitude toward life.

In this respect, a 56-year-old man explained:

"After my diagnosis, my way of living and opinions about life have changed...I try very hard to live everyday...I have become very serious about life."

In another case, a 70-year-old man told us the following:

"When I got cancer, 14 years ago...I decided to do the things I like while I was still alive and made a plan for how to live the rest of my life. I travelled abroad. And I changed my diet...Also, I tried to keep myself in a good state of mind, not be angry... I feel grateful for what cancer gave me."

This idea is also found in the response of another interviewee, a 61-year-old woman:

"I realized that cancer is not all bad. So it's important for us to find the good things cancer can bring."

The use of positive thinking as a coping method among Japanese cancer patients can be related to the impact of Buddhist teachings. As Low (2010) explains, "action-oriented Buddhism upholds and in fact advances positive thinking."

There are, however, different interpretations of the teachings of Buddhism concerning positive thinking; some believe that Buddhism does not advocate positive thinking and some believe that it does so very strongly. Such a discussion is academic and philosophical in nature. What is important for our study is the fact that these teachings have impacted the ways of thinking of some people in Japanese society. The issue of whether or not these teachings are accurate is not crucial to our analysis.

\section{Conclusion}

The aim of the present study was to answer two questions; one concerned the different meaning-making coping methods used by Japanese cancer patients, and the other concerned the role of culture and ways of thinking in the choice of these methods. We tried to answer both questions by showing how the citations were linked to each coping method and the cultural features that provide the background to use of these methods by Japanese patients. It should be remembered that contemporary Japanese culture is highly diverse and that the religions are pragmatic in nature. Most Japanese go through a Shinto-/Christian-style ceremony when they marry and have a Buddhist-style funeral. Shinto shrines provide centers for communal festivities, while Buddhist temples are the sites of afterlife activities, from wakes to periodic services for the souls of the dead (Van Wolferen, 1990).

Japanese culture not only reflects the attitudes and concerns of the present day, but also provides a link to the past. In general, although the World Values Survey rates Japan as highest in the world on "secular-rational values" (WVS, 2014), contemporary Japanese culture is mainly the result of an intersection and combination of ancient Japanese 
religion (Shintoism), Zen Buddhism, Confucian teachings and the values, virtues and ways of thinking of the long feudal period governed by the samurai class (Mason \& Ciager, 1997). It is also important to remember the influence of modern culture, especially after Japan opened up to the world during the $19^{\text {th }}$ century (Haffner, Casas, Klett \& Lehmann, 2009)

\section{Limitations and Suggestion for Further Studies}

The most imitation of this study concerns the fact that the participants were older than 65 years-old and only one participant was 56 years-old. The meaning-making coping is surely different among younger people compared to those who are older.

Furthermore, it should be noted that all of our patients have not necessarily come into contact with all of the cultural teachings discussed above. Hence, people also choose their coping strategies based on their own personal experiences and social characteristics. In our view, the concept of accessibility should be added to cultural background when studying the reasons why people suffering from illness or dealing with a crisis make use of one or more coping methods.

Despite these limitation, the present study shows us that the different existential coping methods are important and when existential questions come into the picture in coping, we should seriously take them - even non-religious coping methodsinto consideration.

The study shows clearly the impact of culture on choice of coping methods. An investigation on the cultural context is essential then when we explore coping resources and meaning-making experiences among cancer patients. For more understanding of the role of culture in coping and the importance of the non-religious meaning making coping researchers should perhaps design a longitudinal study to investigate the changing patterns of coping and meaning-making among cancer survivors living in different countries.

\section{References}

Ahmadi, F. (2006). Culture, Religion and Spirituality in Coping: The Example of Cancer Patients in Sweden. Uppsala: Acta Universitatis Upsaliensis.

Ahmadi, F. (Ed.). (2015). Coping with Cancer in Sweden - A Search for Meaning. Uppsala: Acta Universitatis Upsaliensis.

Ahmadi, F., \& Ahmadi, N. (2015). Nature as the most important coping strategy among cancer patients - A Swedish survey. Journal of Religion and Health, 52(4), 1177-1190. https://doi.org/10.1007/s10943-013-9810-2

Ahmadi, F., \& Ahmadi, N. (2018). Existential meaning-making for coping with serious illness: Studies in secular and religious societies. London: Routledge. https://doi.org/10.4324/9781315098036

Ahmadi, F., Khodayarifard, M., Rabbani, M., Zandi, S., \& Sabzevari, M. (Forthcoming). Secular existential meaning-making coping: The case of cancer patients in Iran.

Ahmadi, F., Khodayarifard, M., Zandi, S., Khorrami-Markani, A., Ghobari-Bonab, B., Sabzevari, M., \& Ahmadi, N. (2018). Religion, culture and illness: a sociological study on religious coping in Iran. Mental Health, Religion \& Culture, 21(7), 721-736. https://doi.org/10.1080/13674676.2018.1555699

Ahmadi, F., Park, J, Kim, K. M., \& Ahmadi, N. (2017). Meaning-making coping among cancer patients in Sweden and South Korea: A comparative perspective. Journal of religion and Health. 'Online First'. http://link.springer.com/article/10.1007/s10943- 017-0383-3

Ahmadi, F., Park, J., Kim, M. K., \& Ahmadi, N. (2016). Exploring existential coping resources: the perspective of Koreans with cancer. Journal of Religion and Health. https://doi.org/10.1007/s10943-016-0219-6

Aldwin, C. M. (2000). Stress, Coping and Development. New York: Guilford Press.

Astor, D., \& Xi-Ken. (2014). Solitude and the Socially Engaged Monk. Retrieved from https://orderengagedbuddhists.com/2014/03/17/solitude-and-the-socially-engaged-monk/

Braun, V., \& Clarke, V. (2006). Using thematic analysis in psychology. Qualitative Research in Psychology, 3(2), 77-101. ISSN 1478-0887. https://doi.org/10.1191/1478088706qp063oa

Chamberlain, B. H. (1883). The Ko-Ji-Ki, Cambridge: Cambridge University Press.

Cobb, M., Puchalski, C. M., \& Rumbold, B. (2012). Oxford textbook of spirituality in healthcare. Oxford: Oxford University Press. https://doi.org/10.1093/med/9780199571390.001.0001

Haffner, J., Casas, I., Klett, T., \& Lehmann, J. (2009). Japan's Open Future. London: Anthem Press. https://doi.org/10.7135/UPO9780857288127 
Heinschel, J. A. (2002). Descriptive study of the interactive guided imagery experience. Journal of Holistic Nursing, 20, 325-347. https://doi.org/10.1177/089801002237591

Iwai, N. (2017). Measuring religion in Japan: ISM, NHK and JGSS. Survey Research and the Study of Religion in East Asia [Power Point slides]. Retrieved from https://www.pewresearch.org/wp-content/uploads/sites/7/2017/11/Religion20171117.pdf

Johnson, F. A. (1993). Dependency and Japanese socialization: Psychoanalytic and Anthropological Investigations on Amae. Japan: NYU Press.

Jordan, D. K. (1998). Filial Piety in Taiwanese Popular Thought, in Slot, Walter H.; Vos, George, A. De, Confucianism and the Family (pp. 267-84). SUNY Press, ISBN 978-0-7914-3736-0

Koenig, H. G., King, D. E., \& Carson, V. B. (2012). Handbook of religion and health. New York: Oxford University Press.

Kwan, K. L. K. (2000). Counseling Chinese peoples: Perspectives of Filial Piety. Asian Journal of Counseling, 7(1), 23-41.

La Cour, P., \& Hvidit, N. C. (2010). Research on meaning-making and health in secular society: Secular, spiritual and religious existential orientations. Social Science Medicine, 71(7), 1292-1299. https://doi.org/10.1016/j.socscimed.2010.06.024

Lincoln, Y. S., \& Guba, E. G. (1985). Naturalistic Inquiry. Sage Publications. ISBN 0-8039-2431-3. https://doi.org/10.1016/0147-1767(85)90062-8

Low, K. C. P. (2010). Buddha, Buddhism and Positive Thinking - The Way Forward in Our Lives. Insights to a Changing World, 3, 115-124.

Mason, R. H. P., \& Caiger, J. G. (1997). A history of Japan. Tuttle Publishing. ISBN 978-0-8048-2097-4. Retrieved on 9 April 2011.

Matthews, A. (2007). The Way of the Warrior. Usborne Books. ISBN 0746076355

Morioka, K. (1984). Ancestor Worship in Contemporary Japan: Continuity and Change. Senri Ethnological Studies, 11, 201-213. https://doi.org/10.15021/00003371

Moylan, M. M., Carey, L. B., Blackburn, R., Hayes, R., \& Robinson, P. (2015). The Men's Shed: Providing biopsychosocial and spiritual support. Journal of Religion and Health, 54(1), 221-234. https://doi.org/10.1007/s10943-013-9804-0

Naseem, Z., \& Khalid, R. (2010). Positive Thinking in Coping with Stress and Health outcomes: Literature Review. Journal of Research and Reflections in Education June, 4(1), 42 -61. Retrieved from http://www.ue.edu.pk/jrre

Nitobe, I. (2002). Bushido: The Soul of Japan. Tokyo: Kodansha International. ISBN 978-4-7700-2731-3

Padela, A. I., \& Curlin, F. A. (2012). Religion and disparities: Considering the influences of Islam on the health of American Muslims. Journal of Religion and Health, 2(4), 1333-1345. https://doi.org/10.1007/s10943-012-9620-y

Pargament, K. I. (1997). The Psychology of Religion and Coping: Theory, Research, Practice. New York: Guilford Press.

Pargament, K. I. (2007). Spiritually Integrated Psychotherapy: Understanding and Addressing the Sacred, New York: Guilford Press.

Poole, R., \& Higgo, R. (2010). Psychiatry, religion and spirituality: A way forward. The Psychiatrist, $34(10)$, $452-453$. https://doi.org/10.1192/pb.34.10.452b

Powell, L. H., Shahabi, L., \& Thoresen, C. E. (2003). Religion and spirituality: Linkages to physical health. American Psychologist, 58(1), 36-52. https://doi.org/10.1037/0003-066X.58.1.36

Salander, P. (2015). Introduction: A critical discussion on the concept of spirituality in research on health. In F. Ahmadi [Ed.], Coping with cancer in Sweden: A search for meaning (pp. 13-27). Uppsala: Uppsala University.

Sarvananda. (2012) Solitude and Loneliness: A Buddhist View. Windhorse Publications. ISBN: 9781907314070

Shafer, K., \& Greenfield, F. (2000). Asthma Free in 21 Days: The Breakthrough Mindbody Healing Program. New York: HarperCollins

Shaner, D. E. (1985). The body mind experience in Japanese Buddhism: A phenomenological Study of Kukai and Dogen. New York: State University of New York Press.

Sharf, R. H. (1993). The Zen of Japanese Nationalism in D. Lopez (Ed.) Curators of the Buddha (p. 111), Chicago: University of Chicago Press. https://doi.org/10.1086/463354 
Sloan, R. P. (2006). Blind faith: The unholy alliance of religion and medicine. New York: St Martin's Press.

Sloan, R. P., \& Bagiella, E. (2001). Spirituality and medical practice: A look at the evidence. American Family Physician 63(1), 33-35.

Sloan, R. P., \& Bagiella, E. (2002). Claims about religious involvement and health outcomes. Annals Behavioral Medicine, 24(1), 14-21. https://doi.org/10.1207/S15324796ABM2401_03

Stephens, D. J. (2009). Confucianism, pragmatism, and socially beneficial philosophy. Journal of Chinese Philosophy, 36(1), 53-67. https://doi.org/10.1111/j.1540-6253.2008.01504.x

Sung, K. T. (2001). Elder Respect: Exploration of Ideals and Forms in East Asia. Journal of Aging Studies, 15(1), 13-26. https://doi.org/10.1016/S0890-4065(00)00014-1

Sung, K. T. (2009). Repayment for Parents Kindness: Buddhist Way, in Sung, K.T., Kim, B.J., Respect for the Elderly: Implications for Human Service Providers, University Press of America (pp. 353-66). ISBN 978-0-7618-4530-0

Taylor, E. B. (1968). The science of culture. In M. H. Fried [Ed.] Readings in Anthropology: Cultural and Anthropology (pp.1-18), New York: Thomas Y. Crowell.

Thoresen, C. E. (1999). Spirituality and health, is there a relationship? Journal of Health Psychology, 4(3), 291-300. https://doi.org/10.1177/135910539900400314

Thoresen, C. E. (2002). Spirituality and health: What's the evidence and what's needed? Annals of Behavioral Medicine, 24(1), 3-13. https://doi.org/10.1207/S15324796ABM2401_02

Traylor, K. L. (1988). Chinese Filial Piety, Eastern Press.

Van Wolferen, K. (1990). The Enigma of Japanese Power. New York: Vintage Books

Watt, P. (2003). Japanese Religions. FSI: SPICE.

Whiting, R. (1989). You Gotta Have Wa. New York: Macmillan Publishing Co.

World Values Survey. (2014). Retrieved from worldvaluessurvey.org/ WVSContents.jsp ?CMSID= Finding

\section{Notes}

Note 1. About 70\% of Japanese profess no religious membership (Iwai, 2017).

Note 2. Amae has been described as a culturally ingrained dependence on authority figures (Johnson, 1993).

Note 3. A kind of exercise through deep breathing, originated from China

Note 4. Kami is a Supreme Being who possesses power beyond human beings. It is not referred to as a Christian God. 


\section{Appendix}

Interview Guide:

BACKGROUND FACTORS:

-Age/Sex/Education/Job (before retirement)/Family/Environment informant grew up/Functional status/Religious orientation/Situational factors/Disease stage/Age of diagnosis/Type of cancer

\section{INTERVIEW QUESTIONS:}

\section{Religiosity:}

1. Are you from a religious family?

2. Do you believe that there is God?

If yes: a. how often do you pray? b. Do you go to church or other religious places now? c. How often?

If no: Do you believe that there is some kind of spiritual being or vital power?

3. Have your spiritual beliefs and religious practices changed, after hitting by cancer?

4. Do you believe in life after death?

Meaning making coping:

5. In period of crisis, how does/did you cope? Who/what does/ did help you?

6. Have religion or spirituality played any role in this respect?

7. Has your illness caused that you asked God/a spiritual being to find a new purpose in life or a total spiritual reawaking?

8. Has nature been an important resource for you deal with your illness?

9. Has been alone and pondering about your life and it meaning been a way to deal with your illness?

10. Have you used any form of Holistic Health in relation to your cancer problem? If yes, was it as an alternative to conventional treatment?

11. Do you regularly meditated in order to deal with your illness?

12. Have you used the visualization in order to deal with your illness?

13. Do you have ever thought that God/a spiritual being allow this event happen to you because of your sins or because of your lack of faith?

14. Do you think that your illness is made by an evil power?

15. Do you work with God/a spiritual being to relive your worries?

16. Do you think that you have done your best and now it is only should give up of control to God/a spiritual being?

17. Do you expect that God/a spiritual being to take your worries away because you know that you cannot handle the situation or do you think that that god can help you to take care of your illness?

18. Do you pray or bargained with God/a spiritual being to make things better?

19. Do you try to deal with the situation on your own without God's/a spiritual being's or any supreme values' help?

20. Have you ever experienced a sense of strong connection with God/a spiritual being?

21. Have you ever experienced a sense of spiritual connection with other people?

22. Have you ever thought that your life is part of a larger higher power?

23. Have you ever experienced a stronger feeling of spirituality?

24. Have you ever wondered that god had abandoned you or felt angry that God/a spiritual being was not here for you?

25. Do you look for spiritual support from clergy?

26. Do you give spiritual strength to others?

\section{Copyrights}

Copyright for this article is retained by the author(s), with first publication rights granted to the journal.

This is an open-access article distributed under the terms and conditions of the Creative Commons Attribution license which permits unrestricted use, distribution, and reproduction in any medium, provided the original work is properly cited. 